\title{
Breast Cancer Screening Tests in Tabriz Behbood Hospital
}

\author{
Fahimeh Sehhatie Shafaie $^{1^{*}}$, Somayyeh Nagizadeh ${ }^{2}$, Soosan Valizadeh ${ }^{3}$
}

\begin{abstract}
Objectives: Considering the prevalence age of breast cancer (BC) as whole and involvement of young aged Iranian women and as Behbood hospital is a screening center for BC in Tabriz, East Azerbaijan, this study aimed to present the results of screening tests. Materials and Methods: For 5000 women referred to BC clinic of Behbood hospital, a self-designed questionnaire including demographic-social characteristics and risk factors of $\mathrm{BC}$ was completed by researcher. Then breasts of women were examined by midwives and recorded in questionnaire. In case of abnormal results ultrasonography, mammography and fine needle aspiration (FNA) were prescribed and results were recorded in the questionnaire.

Results: A total 516 cases of left breast mass and 480 cases of right breast mass were palpated. Forty cases out of 996 ultrasonography were abnormal. A total of 183 cases out of 636 mammography were abnormal. One case out of 14 FNA was cancer (7.1\%). Occupation, menopause status, history of performing FNA, education level, marriage status, age of first pregnancy and body mass index (BMI) had significant relationship with abnormal clinical breast examination (CBE). Breastfeeding had significant relationship with abnormal sonography results. Menopause, diet, use of chemical agents and type of oils used in diet had significant relationship with abnormal mammography results $(P<0.05)$.

Conclusion: Based on these results, women should be encouraged to undergo BC screening tests more regularly and to increase their knowledge on $\mathrm{BC}$ and benefits of screening through public media.

Keywords: Breast cancer, Cancer screening tests, Fine needle aspiration, Mammography, Ultrasonography
\end{abstract}

\section{Introduction}

Breast cancer (BC) composes about one-third of all cancers among women and is considered as the most prevalent cause of cancer death after lung cancer among women. At present, one out of seven American women suffer from $\mathrm{BC}$ in their lives (1). One out of 8 Iranian women aged 40-55 years old suffer from BC. The age of occurrence of this disease in our society is about one decade lower than the global mean (2). In America, about 192370 women are added to the cancer list yearly and from among them, 40170 ones die (3). According to the study by Mousavi et al, cancer is the third most prevalent cause of death in Iran and the age specific of BC rate in Iran is 98 in 100000 (9.8\%) (4), which was 19.25\% in Golestan province according to the study by Marjani and Kabir (5). Risk factors involved in BC include age, gender, family history, hormones, pregnancy record, premature menarche, menopause, oral contraceptives, hormone replacement therapy, inheritance, previous history of benign breast diseases, previous history of BC diagnosis, $\mathrm{x}$-ray exposure, life style (dietary, alcohol consumption), breastfeeding, etc. (6). Although this disease has high prevalence, the important point is its early and on-time diagnosis which is considered as the most important factor in BC treatment. If treatment is done in primary stages (less than 1 $\mathrm{cm}$ mass), the result will be $90 \%$ successful (7).

The effective methods for screening breast cancer is clinical breast examination (CBE) and mammography (8). CBE helps finding cancer and other palpable breast masses and proposes mammography for exploring impalpable $\mathrm{BC}$ at early stages of development. CBE is done with mammography while it is not replaced by mammography (9). The primary goal of mammography is screening women without symptom for finding BC at primary stages. Screening with mammography among women of 40 years and older, reduces the mortality by $20 \%$ to $30 \%$ (10). The effective screening provides the possibility of primary and secondary prevention of disease for reducing the lesions (11). In fact, screening aims at finding the cancer when they are small (less than $1 \mathrm{~cm}$ ) and there is most probability of recovery or surgery. The results of Gothenburg screening showed that the mortality reduces by $45 \%$ among $40-49$ years old women who were screened (1). Screening for BC is necessary for all women in critical ages (10). For women without risk factor, $\mathrm{CBE}$ is done once a year in women older than 30 years old and it is done every 1-3 years for women below 30 years of age. Mammography is done every 1-2 years in 40-49 years old women and it is done yearly in 50-69 years old women (12). CBE should be done once every three years from 20 years of age and annually 
from 40 years of age; in case of a worrying situation, it should be performed at younger ages (13).

According to Olyaeemanesh et al, BC is the most prevalent cancer among Iranian women, and thus screening should be started in Iran at younger ages (14). American Cancer Society (ACS) proposes that women above 30 years and without any symptom, receive CBE as BC screening test permanently and regularly (15). Currently in Iran, CBE is the best screening method for all women while performing mammography for people with more risk (16). On the other hand, midwives are the first individuals from the health team who face women and can play a key role in detecting and referring women with breast mass in the screening process. According to the studies, replacement of general surgeon instead of midwife, as first examiner for clinical screening of $\mathrm{BC}$, is not certified in the general health system (17).

Unfortunately, most of the people refer when cancer is in an advanced level, thus, it seems necessary to train them in regard to self-breast examination and performing screening test at proper ages (18).

Executing precise training programs in the society and increasing the quality of health cares and conducting screening tests (CBE and mammography) at health and treatment centers can be a big step in premature exploring of breast masses including benign and malignant, reducing the treatment expenses and reducing the mortality among women. Also it can play a big and valuable role in improving life quality and reducing the complications resulting from mothers' premature death (19).

BC clinic of Behbood hospital was established in March 2007. In this center mammography, ultrasonography, fine needle aspiration (FNA) and other paraclinical methods are performed and if needed the patient is referred to different governmental treatment centers. By now, about 21000 patients have been examined. Regarding the prevalence of BC and low age of prevalence in Iranian society, we decided to study the risk factors and screening methods of BC among those referring to BC clinic of Behbood hospital to inform the health-treatment centers from the results of these actions. So that it could be a starting point for such activities in other clinics and hospitals and a step towards early diagnosis of breast masses including benign and malignant.

\section{Materials and Methods}

The current study is a descriptive one. Target population were women referring for screening to BC clinic of Behbood hospital. This study started in 2010 on 5000 women and finished in 2014. Convenience sampling was done and criteria for entering the study included all women older than 15 years, referring to BC clinic of Behbood hospital, who were willing to participate in the study and could answer the questions in the questionnaire.

The excluding criteria included non-willingness for participation in the study. The sample size was computed by available $\mathrm{P}=7 \%$ in review of literature and using the following formula with $95 \%$ reliability and 5\% error at 5000 ones $(\mathrm{N}=\mathrm{pqz} 2 / \mathrm{d} 2)$.

The content validity was used for determining the validity of the research such that the questionnaire was given to 10 internal and external professors at the Tabriz Faculty of Nursing and Midwifery and having studied them, the required amendments were done. It was finalized and then used for research samples. For reliability of CBE, simultaneous examination was used such that clinical examination was done by two of trained researchers on 10 research samples and then the reliability of it was computed $(r=0.87)$.

\section{Procedure}

The self-designed questionnaire which included demographic-social characteristics and risk factors of BC, was completed privately for all the women above 15 years old referring to Breast clinic of Behbood hospital in 2010. After obtaining consent, the breasts were examined by the physician or midwife and the results were recorded on special sheets and if the results were abnormal, the physician requested mammography, ultra sonography, FNA and serology tests and the results were registered in the questionnaire. The next referring time was defined and regarding the results, the physician made decision for type of treatment. Finally, data were analyzed by SPSS 21, descriptive statistical tests (mean and standard deviation) and chi-square test.

\section{Approach}

1- Acceptance of the cost of performing certain tests in patients by research planner.

2- Participation of psychologist colleagues for counselling.

\section{Results}

The findings show that most of the samples were in the 20 -39 years age group (55.9\%) and the mean age of people was 37.485 years $(10.81 \%)$. Most of the women had primary education (38\%) and more than $80 \%$ were housewives. The job of most of the employed ones were non-administrative $(5.5 \%)$ and more than $80 \%$ were residing in the city $(88.4 \%)$.

Most of the women were married (91.9\%). In $85 \%$ of women, the income was less than the cost. More than $70 \%$ of samples did not have history of infertility and used non-hormonal contraceptive methods (75.4\%). Most of the women had normal body mass index (BMI) (3.3\%); mean BMI was 27.33 (SD: 4.8). The mean of pregnancy in married women was 2.5 (SD: 1.61) and most of them had one pregnancy $(68.8 \%)$. Most of the married ones had one child $(71.6 \%)$ and had at least one time breastfeeding record $(54.6 \%)$.

The mean of menarche age was 12.61 years (SD: 1.33 ), with age range of 10-19 years (88.2\%), the mean of first pregnancy was 2.91 (SD: 4.17 ) and about $50 \%$ of them had a age range of 18-39 years. Most had A Rh+ blood group $(20.8 \%), 87.9 \%$ had family history of benign breast disease, $96 \%$ did not have FNA record and/or radiotherapy (96.9\%). About $70 \%$ of people did not have hormone 
replacement therapy (HRT) and more than $90 \%$ of them did not have BC record and only $0.3 \%$ had such a record. 93.4\% of samples did not have BC history in their first rank relatives before menopause and $92.8 \%$ did not have such history after menopause.

Regarding the life style, the results showed that most of the people (83.7\%) had low-fat diet; about 90\% used $2-3$ spoons of oil daily and type of consumed oil was liquid oil (56.3\%). About $65 \%$ of women did not have plant protein consumption, while $97 \%$ regularly used fruits and vegetables. Seventy-seven percent of samples did not use detergents in their homes and only used it once in a week. Unfortunately, the type of pollutant in most of the samples was unknown (76.4\%) and detergents were not used very oftenly $(15.5 \%)$. Most of the participants in the research did not smoke (97.9\%) or consume alcohol (76.4\%); unfortunately most of the women did not do exercises (87\%) and only $11.7 \%$ of women exercised which was mostly jogging, swimming and mountain climbing.

Among patients undergoing CBE, 516 masses were palpated in left breast and 480 masses in right breast; totally 759 had abnormal examination results and the remaining were normal. From among 996 sonographies done, 40 were abnormal and the remaining were normal. Unfortunately only 14 FNA results were returned to Center for BC screening and from among them one cancer was reported. Patient's occupation, menopause, benign breast disease history in the family, history of doing FNA, academic status, marital status, number of children, number of pregnancies, age, age of first pregnancy and BMI had significant relationship with breast mass (Tables 1 and 2) and breastfeeding frequency had significant relationship with abnormal sonography results (Table 3). Also menopause, diet, exposure to pollutants, types of pollutant and type of dietary oil used had significant relationship with abnormal results of mammography (Table 4).

Table 1. Relationship Between Demographic-Social-Midwifery Characteristic With Clinical Breast Examination (CBE) Results in Left Breast

\begin{tabular}{|c|c|c|c|c|}
\hline \multirow{2}{*}{ Variable } & & \multicolumn{2}{|c|}{ Mass in left breast } & \multirow{2}{*}{ Statistical tests } \\
\hline & & Mass & Without mass & \\
\hline \multirow{5}{*}{ Age (year) } & $<20$ & $34(24.1)$ & $107(75.9)$ & \multirow{5}{*}{$\mathrm{R}=33.17, \mathrm{df}=3, P=0.00$} \\
\hline & $20-39$ & 316 (12.9) & $2140(87.1)$ & \\
\hline & $40-59$ & $152(9.4)$ & $1470(90.6)$ & \\
\hline & $>60$ & $13(9.4)$ & $126(90.6)$ & \\
\hline & Mean (SD) & $37.45(10.81)$ & & \\
\hline \multirow{4}{*}{ Age of first pregnancy } & $<18$ & $97(8.9)$ & 987 (91.1) & \multirow{4}{*}{$\mathrm{R}=21.49, \mathrm{df}=2, P=0.04$} \\
\hline & $18-39$ & $260(11.8)$ & $1946(88.2)$ & \\
\hline & $>40$ & $13(10.2)$ & $114(89.8)$ & \\
\hline & Mean (SD) & $20.91(4.17)$ & & \\
\hline \multirow{4}{*}{ Number of pregnancy } & 1 & 345 (11.4) & $2676(88.6)$ & \multirow{4}{*}{$\mathrm{R}=6.08, \mathrm{df}=2, P=0.04$} \\
\hline & $2-9$ & $50(8.3)$ & $552(91.7)$ & \\
\hline & $>10$ & $9(7.9)$ & $105(92.1)$ & \\
\hline & Mean (SD) & $2.5(1.61)$ & & \\
\hline \multirow{4}{*}{ Number of children } & 1 & $357(11.4)$ & $2786(88.6)$ & \multirow{4}{*}{$\mathrm{R}=8.77, \mathrm{df}=2, P=0.01$} \\
\hline & $2-9$ & $33(7)$ & 441 (93) & \\
\hline & $>10$ & $5(8.1)$ & 57 (91.9) & \\
\hline & Mean (SD) & $2.3(1.3)$ & & \\
\hline \multirow{2}{*}{ Occupation } & Housewife & $393(86)$ & $3139(90.4)$ & \multirow{2}{*}{$\mathrm{R}=8.42, \mathrm{df}=1, P=0.003$} \\
\hline & Employed & $64(14)$ & 335 & \\
\hline \multirow{4}{*}{ Breastfeednig times } & 1 & $271(11.4)$ & $2114(88.6)$ & \multirow{4}{*}{$\mathrm{R}=6.10, \mathrm{df}=3, P=0.10$} \\
\hline & $2-9$ & $81(10.4)$ & $700(89.6)$ & \\
\hline & $>10$ & $13(6.3)$ & $193(93.7)$ & \\
\hline & Unknown & $4(17)$ & $53(93)$ & \\
\hline \multirow{2}{*}{ Menopause } & Yes & 477 (92.4) & $3406(88.3)$ & \multirow{2}{*}{$\mathrm{R}=6.89, \mathrm{df}=1, P=0.002$} \\
\hline & No & $39(7.6)$ & $452(11.7)$ & \\
\hline \multirow{2}{*}{ FNA record } & Yes & $7(1.4)$ & $7(0.2)$ & \multirow{2}{*}{$\mathrm{R}=19.30, \mathrm{df}=1, P=0.001$} \\
\hline & No & $497(98.6)$ & 3703 (99.8) & \\
\hline \multirow{2}{*}{ Marital status } & Divorced.widowed.married & $454(89)$ & $3581(94.5)$ & \multirow{2}{*}{$\mathrm{R}=23.22, \mathrm{dF}=1, P=0.001$} \\
\hline & Single & $56(11)$ & & \\
\hline \multirow{3}{*}{ Academic status } & Primary & $173(43)$ & $1488(50.8)$ & \multirow{3}{*}{$\mathrm{R}=8.67, \mathrm{df}=2, P=0.01$} \\
\hline & High school diploma & $150(37.3)$ & $961(32.8)$ & \\
\hline & Above high school diploma & 79 (19.7) & $480(16.4)$ & \\
\hline \multirow{2}{*}{ Economic status } & Income less than cost & $444(96.3)$ & $3309(95.1)$ & \multirow{2}{*}{$\mathrm{R}=0.35, \mathrm{df}=1, P=0.32$} \\
\hline & Income more than cost & $17(3.7)$ & $148(4.3)$ & \\
\hline \multirow{2}{*}{ Method of contraception } & Hormonal & $360(93)$ & $2943(91.2)$ & \multirow{2}{*}{$\mathrm{R}=1.42, \mathrm{df}=1, P=0.13$} \\
\hline & Non-hormonal & $27(7)$ & $283(8.8)$ & \\
\hline Propetfoeding durntion in the lat shild & Less than 24 months & $58(10.3)$ & $506(89.7)$ & $-0 \wedge 0 \mathrm{df}-1-P=030$ \\
\hline Breastieeaing auration in the last cnima & More than 24 months & $22(18)$ & $227(91.2)$ & $K=0.40, \mathrm{di}=1, P=0.30$ \\
\hline
\end{tabular}


Table 2. Relationship Between Demographic-Social-Midwifery Characteristic With Clinical Breast Examination (CBE) Results in Right Breast

\begin{tabular}{|c|c|c|c|c|}
\hline \multirow{2}{*}{ Variable } & & \multicolumn{2}{|c|}{ Mass in left breast } & \multirow{2}{*}{ Statistical tests } \\
\hline & & Mass & Without mass & \\
\hline \multirow{5}{*}{ Age (year) } & $<20$ & $26(19.3)$ & $109(80.7)$ & \multirow{5}{*}{$\mathrm{R}=21.49, \mathrm{df}=3, P=0.00$} \\
\hline & $20-39$ & $299(12.2)$ & $2142(87.8)$ & \\
\hline & $40-59$ & $141(8.8)$ & 1457 (91.2) & \\
\hline & $>60$ & $12(8.8)$ & $124(91.2)$ & \\
\hline & Mean (SD) & $37.45(10.81)$ & & \\
\hline \multirow{4}{*}{ Age of first pregnancy } & $<18$ & $95(8.8)$ & $981(91.2)$ & \multirow{4}{*}{$\mathrm{R}=4.89, \mathrm{df}=2, P=0.08$} \\
\hline & $18-39$ & $232(10.7)$ & $1944(89.3)$ & \\
\hline & $>40$ & $18(10.2)$ & $109(85 / 8)$ & \\
\hline & Mean (SD) & $20.91(4.17)$ & & \\
\hline \multirow{4}{*}{ Number of pregnancy } & 1 & $152(14)$ & $932(86)$ & \multirow{4}{*}{$\mathrm{R}=15.45, \mathrm{df}=2, P=0.00$} \\
\hline & $2-9$ & $147(10.1)$ & $1315(89.9)$ & \\
\hline & $>10$ & $95(9.1)$ & $952(90.9)$ & \\
\hline & Mean (SD) & $27.33(4.8)$ & & \\
\hline \multirow{4}{*}{ Number of children } & 1 & $314(10.1)$ & 2786 (89.9) & \multirow{4}{*}{$\mathrm{R}=2.52, \mathrm{df}=2, P=0.28$} \\
\hline & $2-9$ & 37 (7.9) & $432(92.1)$ & \\
\hline & $>10$ & $7(11.7)$ & $53(88.3)$ & \\
\hline & Mean (SD) & $2.3(1.3)$ & & \\
\hline \multirow{2}{*}{ Occupation } & Housewife & 789 (90.7) & 31 (91.2) & \multirow{2}{*}{$\mathrm{R}=0.0, \mathrm{df}=1, P=0.61$} \\
\hline & Employed & $81(9.3)$ & $3(8.8)$ & \\
\hline \multirow{4}{*}{ Breastfeednig times } & 1 & $249(10.6)$ & 2107 (89.4) & \multirow{4}{*}{$\mathrm{R}=3.67, \mathrm{df}=3, P=0.29$} \\
\hline & $2-9$ & $63(8.2)$ & $703(91.8)$ & \\
\hline & $>10$ & $19(9.3)$ & $185(90.6)$ & \\
\hline & Unknown & $6(10.7)$ & $50(89.3)$ & \\
\hline \multirow{2}{*}{ Menopause } & Yes & $454(94.6)$ & $3390(88.1)$ & \multirow{2}{*}{$\mathrm{R}=17.87, \mathrm{df}=1, P=0.00$} \\
\hline & No & $26(5.4)$ & 456 (11.9) & \\
\hline \multirow{2}{*}{ FNA record } & Yes & $6(1.3)$ & $6(0.2)$ & \multirow{2}{*}{$\mathrm{R}=18.10, \mathrm{df}=1, P=0.001$} \\
\hline & No & $463(98.7)$ & 3695 (99.8) & \\
\hline \multirow{2}{*}{ Marital status } & Divorced/widowed/married & $421(88.5)$ & $3571(94.5)$ & \multirow{2}{*}{$\mathrm{R}=23.28, \mathrm{dF}=1, P=0.00$} \\
\hline & Single & $53(11.2)$ & $209(5.5)$ & \\
\hline \multirow{3}{*}{ Academic status } & Primary & $173(44.6)$ & $1473(50.5)$ & \multirow{3}{*}{$\mathrm{R}=5.19, \mathrm{df}=2, P=0.07$} \\
\hline & High school diploma & $140(36.1)$ & $969(33.2)$ & \\
\hline & Above high school diploma & 75 (19.3) & $474(16.3)$ & \\
\hline \multirow{2}{*}{ Economic status } & Income less than cost & $391(65.1)$ & 3307 (95.9) & \multirow{2}{*}{$\mathrm{R}=0.0, \mathrm{df}=1, P=0.61$} \\
\hline & Income more than cost & $20(4.9)$ & $142(4.1)$ & \\
\hline \multirow{2}{*}{ Method of contraception } & Hormonal & $324(90.5)$ & $2952(91.6)$ & \multirow{2}{*}{$\mathrm{R}=0.49, \mathrm{df}=1, P=0.26$} \\
\hline & Non-hormonal & $34(9.5)$ & $271(8.4)$ & \\
\hline Breastfeeding duration in the last child & Less than 24 months & $53(9.4)$ & $510(90.6)$ & $R=0.0 \mathrm{df}=1 \quad P=0.51$ \\
\hline Breastreeaing auranon in the last cnila & More than 24 months & $23(9.6)$ & $217(90.4)$ & $\mathrm{R}=0.0, \mathrm{ar}=1, P=0.51$ \\
\hline
\end{tabular}

\section{Discussion}

The results of research showed that 5000 women participated in the screening program. Regarding the age, most of them were in 20-39 years age group, had primary education, were housewives and resided in city. Most of the samples were divorced/married or widowed, did not have good economic status, had $\mathrm{A} \mathrm{Rh}^{+}$blood group, did not have any infertility history and did not use hormonal methods for contraception. Most of the samples had normal BMI, were pregnant at least once, had at least one child and had one breastfeeding history. Most of them had menarche around 12 years of age, experienced their first pregnancy at the age of 21 years, had no record of benign disease in the family or had no record of FNA or radiotherapy. Most of them had no treatment record of HRT, $\mathrm{BC}$ record, and $\mathrm{BC}$ record in first rank relatives before and after menopause. The above findings are fully consistent with the results of study by Hosseinzadeh et al (20).
Naghibi et al in their study announced the rate of CBE or breast palpation at 4 to $25 \%$ (21), while Salimi Pormehr et al in their research conducted among women referring to Ardebil treatment and health centers reported CBE at $4.7 \%$ (22) and Farshbaf et al reported it at $19.1 \%$ which is almost similar to the current study (23). Individual's occupation, menopause, history of breast disease in the family, history of FNA, education status, marital status, number of children, number of pregnancy, age, age of first pregnancy and BMI had significant relationship with abnormal breast examination. These findings i.e. educational status and history of benign breast disease in the family are consistent with the results of study by Hosseinzadeh et al (20), Braaten et al (24) and Cunningham et al (25) regarding the economic-social status (education level and income). The economic-social factors and life style factors like diet and physical activity can influence fertility behaviors such as infertility, age at first pregnancy, number of 
Table 3. Relationship Between Demographic-Social-Midwifery Characteristic With Abnormal Breast Sonography Results

\begin{tabular}{|c|c|c|c|c|}
\hline \multirow{2}{*}{ Variable } & & \multicolumn{2}{|c|}{ Abnormal sonography } & \multirow{2}{*}{ Statistical tests } \\
\hline & & Mass & Without mass & \\
\hline \multirow{5}{*}{ Age (year) } & $<20$ & $41(100)$ & $0(0)$ & \multirow{5}{*}{$\mathrm{R}=2.88, \mathrm{df}=3, P=0.41$} \\
\hline & $20-39$ & $661(96.2)$ & $26(3.8)$ & \\
\hline & $40-59$ & $23.5(94.8)$ & $13(5.2)$ & \\
\hline & $>60$ & $17(94.4)$ & $1(5.6)$ & \\
\hline & Mean (SD) & \multicolumn{2}{|c|}{$37.45(10.81)$} & \\
\hline \multirow{4}{*}{ Age of first pregnancy } & $<18$ & $222(98.2)$ & $4(1.8)$ & \multirow{4}{*}{$\mathrm{R}=4.47, \mathrm{df}=2, P=0.10$} \\
\hline & $18-39$ & $498(95.6)$ & $23(4.4)$ & \\
\hline & $>40$ & $742(96.2)$ & $29(3.8)$ & \\
\hline & Mean (SD) & \multicolumn{2}{|c|}{$20.91(14.17)$} & \\
\hline \multirow{4}{*}{ BMI } & Thin & $267(97.8)$ & $6(2.2)$ & \multirow{4}{*}{$\mathrm{R}=0.37, \mathrm{df}=2, P=0.82$} \\
\hline & Normal & $323(94.4)$ & $19(5.6)$ & \\
\hline & Fat and overweight & $198(96.6)$ & $7(3.4)$ & \\
\hline & Mean (SD) & \multicolumn{2}{|c|}{$27.33(4.8)$} & \\
\hline \multirow{4}{*}{ Breastfeednig times } & 1 & $557(96.7)$ & $19(3.3)$ & \multirow{4}{*}{$\mathrm{R}=9.69, \mathrm{df}=3, P=0.02$} \\
\hline & $2-9$ & $149(93.1)$ & $11(6.9)$ & \\
\hline & $>10$ & $25(100)$ & $0(0)$ & \\
\hline & Unknown & $3(75)$ & $1(25)$ & \\
\hline \multirow{2}{*}{ Menopause } & Yes & $906(94.6)$ & $37(92.5)$ & \multirow{2}{*}{$\mathrm{R}=0.31, \mathrm{df}=1, P=0.38$} \\
\hline & No & $52(5.4)$ & $3(7.5)$ & \\
\hline \multirow{2}{*}{ Marital status } & Divorced/widowed/married & $864(92)$ & $39(97.5)$ & \multirow{2}{*}{$\mathrm{R}=1.61, \mathrm{dF}=1, P=0.16$} \\
\hline & Single & $75(8)$ & $1(2.5)$ & \\
\hline \multirow{3}{*}{ Academic status } & Primary & $389(51.7)$ & $19(61.3)$ & \multirow{3}{*}{$\mathrm{R}=2.13, \mathrm{df}=2, P=0.34$} \\
\hline & High school diploma & $266(53.3)$ & $7(22.6)$ & \\
\hline & Above high school diploma & $98(1.3)$ & $5(16.1)$ & \\
\hline \multirow{2}{*}{ Economic status } & Income less than cost & $837(96.7)$ & $34(94.4)$ & \multirow{2}{*}{$\mathrm{R}=0.50, \mathrm{df}=1, P=0.35$} \\
\hline & Income more than cost & $29(3.3)$ & $2(5.6)$ & \\
\hline
\end{tabular}

Table 4. Relationship Between Demographic-Social-Midwifery Characteristic With Abnormal Breast Mammography Results

\begin{tabular}{|c|c|c|c|c|}
\hline \multirow{2}{*}{ Variable } & & \multicolumn{2}{|c|}{ Abnormal mammography } & \multirow{2}{*}{ Statistical tests } \\
\hline & & Mass & Without mass & \\
\hline \multirow{5}{*}{ Age (year) } & $<20$ & $2(100)$ & $0(0)$ & \multirow{5}{*}{$\mathrm{R}=1.75, \mathrm{df}=3, P=0.62$} \\
\hline & $20-39$ & $47(75.8)$ & $15(24.2)$ & \\
\hline & $40-59$ & $376(70.7)$ & $156(29.3)$ & \\
\hline & $>60$ & $25(67.6)$ & $12(32.4)$ & \\
\hline & Mean (SD) & \multicolumn{2}{|c|}{$37.45(10.81)$} & \\
\hline \multirow{4}{*}{ Age of first pregnancy } & $<18$ & $161(74.2)$ & $56(25.8)$ & \multirow{4}{*}{$\mathrm{R}=0.84, \mathrm{df}=2, P=0.65$} \\
\hline & $18-39$ & $218(70.6)$ & $91(29.4)$ & \\
\hline & $>40$ & $13(72.2)$ & $5(27.8)$ & \\
\hline & Mean (SD) & \multicolumn{2}{|c|}{$20.91(14.17)$} & \\
\hline \multirow{4}{*}{ BMI } & Thin & $64(72.7)$ & $24(27.3)$ & \multirow{4}{*}{$\mathrm{R}=2.32, \mathrm{df}=2, P=0.31$} \\
\hline & Normal & $181(78.4)$ & $50(21.6)$ & \\
\hline & Fat and overweight & $153(72.5)$ & $58(27.5)$ & \\
\hline & Mean (SD) & & 4.8) & \\
\hline \multirow{2}{*}{ Diet } & High fat & $77(17.1)$ & $14(7.7)$ & \multirow{2}{*}{$\mathrm{R}=9.40, \mathrm{df}=1, P=0.001$} \\
\hline & Low fat & $374(82.9)$ & $169(92.3)$ & \\
\hline \multirow{2}{*}{ Menopause } & Yes & $383(84.5)$ & $135(73.8)$ & \multirow{2}{*}{$\mathrm{R}=10.01, \mathrm{df}=1, P=0.001$} \\
\hline & No & $70(15.5)$ & $48(26.2)$ & \\
\hline \multirow{2}{*}{ Use of detergent } & Yes & $89(20.6)$ & $24(13.5)$ & \multirow{2}{*}{$\mathrm{R}=4.23, \mathrm{dF}=1, P=0.02$} \\
\hline & No & $343(79.4)$ & $154(86.5)$ & \\
\hline \multirow{3}{*}{ Type of oil used } & Solid oil-butter & $172(39.1)$ & $51(29.1)$ & \multirow{3}{*}{$\mathrm{R}=12.62, \mathrm{df}=2, P=0.00$} \\
\hline & Liquid oil & $240(54.5)$ & $99(56.6)$ & \\
\hline & Both & $28(6.4)$ & $25(14.3)$ & \\
\hline \multirow{2}{*}{ Type of pollutant } & Unknown & $342(82.4)$ & $154(88)$ & \multirow{2}{*}{$\mathrm{R}=2.87, \mathrm{df}=1, P=0.05$} \\
\hline & Detergents & $73(17.6)$ & $21(12)$ & \\
\hline
\end{tabular}


children and breastfeeding duration (20). The findings of current study are consistent with the study of Hadjisavvas et al (26) and Beiler et al (27) regarding the number of children.

From among 996 sonography, 40 were abnormal (0.8\%) and the remaining were normal and only the history of breastfeeding had significant relationship with abnormal sonography results which is consistent with the results of study by Hosseinzadeh et al (20), Ozmen et al (28), Hadjisavvas et al (26) and Collaborative group (29). Breastfeeding can reduce the risk of $\mathrm{BC}$ by two mechanisms i.e. breast tissue differentiation and reduction of the number of ovulatory cycles during the life (20).

From among 636 mammography, 183 were abnormal $(3.66 \%)$ and the remaining were normal. Naghibi et al in their study reported mammography from 3\% to $26 \%$ (21), Salimi Pormehr et al at 3.7\% and Farshbaf et al at 3.3\% which are fully consistent with the current study (22).

Menopause, diet, use of detergents, type of pollutants and type of oil used have significant relationship with abnormal mammography results. These results are consistent with the results of study by Hosseinzadeh et al (20), Larsson et al (30), Boggs et al (31), Balasubramaniam et al (32) and La Vecchia et al (33) regarding the diet (using oily foods, fruits and vegetables).

Therefore increasing women's awareness and knowledge regarding early diagnosis is an essential (21). Khani et al named poverty, lack of health insurance and increasing age as the effective factors in performing CBE among women in different regions of the world and believe that most women with low economic-social status or even education, refrain from breast examination or mammography in most developing countries in spite of having insurance coverage. It seems that lack of awareness in Iranian women regarding the risk factors, diseases symptoms and benefits of executing screening programs and manner of health and treatment clinics function related to $\mathrm{BC}$ results from lack of preventive programs (34).

\section{Limitations}

- Absence of follow-up and co-operation with some of the patients

- Denial of the problem

-

\section{Conclusion}

Since several studies had been conducted in Iran on the $\mathrm{BC}$ screening methods and regarding the difference in designing studies, different results and identifying different factors in some of these papers, performing a systematic review on literature seems suitable.

\section{Ethical Issues}

Local ethical committee approved this study.

\section{Conflict of Interests}

The authors declare no conflict of interests.

\section{Financial Support}

The researchers received no financial support or grant from any funding agency in the public and commercial sectors.

\section{Acknowledgments}

Finally we appreciate all the women who participated in the screening program and our colleagues at Behbood hospital who assisted us in conducting this research.

\section{References}

1. Berek JS, Novak R. Berek \& Novak's Gyneological Diseases. Davari Tanha F, Pourmatroud E, trans. Philadelphia: Lipincott; 2012.

2. Montazeri A, Harirchi I, Harirchi AM, et al. Breast cancer in Iran: need for greater women awareness of warning signs and effective screening methods. Asia Pac Fam Med. 2008:7(1):6. doi:10.1186/1447-056X-7-6.

3. American Cancer Society. Cancer Facts and Figures 2015. Atlanta, Ga: American Cancer Society; 2015.

4. Mousavi SM, Montazeri A, Mohagheghi MA, et al. Breast cancer in Iran:an epidemiological review. Breast J. 2007;13(4):383-391.doi: 10.1111/j.1524-4741.2007.00446.x.

5. Marjani A, Kabir MJ. Breast cancer incidenceamong females in the Golestan province; Iran. Indian J Cancer 2009;46(4):351-352. doi:10.4103/0019-509X.55564.

6. Ligibel J. Obesity and breast cancer. Oncology. 2011;25(11):994-1000.

7. American Joint Committee on Cancer. Breast. In: AJCC Cancer Staging Manual. 7th ed. New York: AJCC; 2010.

8. Pasta V, Gullo G, Giuliani A, Harrath AH, Alwasel SH, Tartaglia F, et al. An Association of boswellia, betaine and myo-inositol in the treatment of mammographic breast density: a randomized, double-blind study. Eur Rev Med Pharmacol Sci. 2015;19(22):4419-4426.

9. Abu-Shammala BI, Abed Y. Breast cancer knowledge and screening behavior among Female school teachers in Gaza city. Asian Pac J Cancer Prev. 2015;16(17):7707-7711.

10. Scott JR, Gibbs RS, Karlan BY, et al. Danforth's Obstetrics and Gynecology. Teimouri M, Bazaz Banaei N, Shafiei A, trans. Philadelphia: Lippincott Williams \& Wilkins; 2008.

11. Ching-Hung H, Todd S. Cancer risk assessment: chemical carcinogenesis, hazard evaluation, and risk quantification. Hoboken, NJ: Wiley; 2010.

12. Rahman M, Mohammed S. Breast cancer metastasis and the lymphatic system. Oncol Lett. 2015;10(3):1233-1239. doi:10.3892/ol.2015.3486.

13. Islam RM, Bell RJ, Billah B, Hossain MB, Davis SR. Awareness of breast cancer and barriers to breast screening uptake in Bangladesh: a population based survey. Maturitas. 2016;84:68-74. doi: 10.1016/j.maturitas.

14. Olyaeemanesh A, Doaee S, Mobinizadeh M, Nedjati M, Aboee P, Emami-Razavi SH. Health technology assessment in Iran: challenges and views. Med J Islam Repub Iran. 2014;28:157.

15. Smith RA, Saslow D, Sawyer KA, et al. American Cancer Society guidelines for breast cancer screening: update 2003. CA Cancer J Clin. 2003;53(3):141-169. doi:10.3322/ canjclin.53.3.141.

16. Dixon JM, editor. ABC of breast disease. Zafarghandi M, trans. 4th ed. Oxford: Wiley-Blackwell; 2012.

17. Bonuck K, Stuebe A, Barnett J, Labbok MH, Fletcher 
J, Bernstein PS. Effect of primary care intervention on breastfeeding duration and intensity. Am J Public Health. 2014;104(S1):S119-S127. doi:10.2105/AJPH.2013.301360.

18. Karimi M. Studying the epidemiologic of breast cancer among patients referring to Shafa hospital in Ahvaz during 2002-2003. Saberin. 2006;22(23):32. [Persian].

19. Sehhatie F. Studying the breast cancer screening method among the ones referring to Tabriz Behbood hospital in 2007. First International Congress on Women Cancers cooperated by IGCS; University of Mashhad; 2008.

20. Hosseinzadeh M, Eivazi ZJ, Mahdavi N, et al. Risk factors for breast cancer in Iranian women: a hospitalbased case-control study in Tabriz, Iran. J Breast Cancer. 2014;17(3):236-243. doi:10.4048/jbc.2014.17.3.236.

21. Naghibi SA, Shojaeizadeh D, Yazdani J, Montazeri A. Studying the preventive behavior of breast cancer and effective factors on it among Iranian women, systematic review of literature, monitoring. Payesh. 2015;14(2):181191.

22. Salimi Pormehr S, Kariman N, Sheikhan Z, Alavimajd H. Studying the breast cancer screening tests and effective factors on it among the women referring to Ardebil health and treatment centers, 2009. J Ardebil Univ Med Sci. 2010;10(4):310-318

23. Farshbaf Khalili A, Shahnazi M, Ghahvehchi A, Torabi S SH. Doing breast cancer screening tests and effective factors on it among the women referring to Tabriz health and treatment centers. Nurs Res. 2009;4(12-13):27-38.

24. Braaten T, Weiderpass E, Kumle M, Adami HO, Lund E. Education and risk of breast cancer in the Norwegian Swedish women's lifestyle and health cohort study. Int J Cancer. 2004;110(4):579-83. doi:10.1002/ijc.20141.

25. Cunningham R, Shaw C, Blakely T, Atkinson J, Sarfati D. Ethnic and scioeconomic trends in breast cancer incidence in New Zealand. BMC Cancer. 2010;10:674. doi: 10.1186/1471-2407-10-674.

26. Hadjisavvas A, Loizidou MA, Middleton N, et al. An investigation of breast cancer risk factors in Cyprus; a case control study. BMC Cancer. 2010;10(1):447. doi: 10.1186/1471-2407-10-447.

27. Beiler JS, Zhu K, Hunter S, Payne-Wilks K, Roland CL, Chinchili VM. A case-control study of menstrual factors in relation to breast cancer risk in African-American women. J Natl Med Assoc. 2003;95(10):930-938.

28. Ozman V, Ozcinar B, Karanlik H, et al. Breast cancer risk factors inTurkish women; a university hospital based nested case control study.World J Surg Oncol. 2009;7(1):1. doi:10.1186/1477-7819-7-37.

29. Collaborative Group on Hormonal Factors in Breast Cancer. Breast cancer and breastfeeding: collaborative reanalysis of indivitual data from 47 epidemiological studies in 30 countries including 50302 women with breast cancer and 96973 women without the disease. Lancet 2002;360(9328):187-195.

30. Larsson SC, Giovannucci E, Wolk A. Folate and risk of breast cancer: a meta-analysis. J Natl Cancer Inst. 2007;99(1):6476.

31. Boggs DA, Palmer JR, Wise LA, et al.Fruit and vegetable intake in relation to risk of breast cancer in the black women's health study. Am J Epidemiol. 2010;172(11):126879. doi: 10.1093/aje/kwq293.

32. Balasubramaniam SM, Rotti SB, Vivekanandam S. Risk factors of female breast carcinoma:a case control study at Puducherry. Indian J Cancer. 2013;50(1):65-70. doi: 10.4103/0019-509X.112307.

33. La Vecchia C, Negri E, Franceschi S, Decarli A, Giacosa A, Lipworth L. Olive oil, other dietary fats, and the risk of breast cancer (Italy). Cancer Causes Control 1995;6(6):545550 .

34. Khani H, Moslemizadeh N, Montazeri A, Godazande GH, Gorbanian A. Knowledge, attitude and performance of health care staff about breast cancer preventive programs in southern border of Khazar sea. Iranian J Breast Dis. 2008;1:28-37.

Copyright (C) 2016 The Author(s); This is an open-access article distributed under the terms of the Creative Commons Attribution License (http://creativecommons.org/licenses/by/4.0), which permits unrestricted use, distribution, and reproduction in any medium, provided the original work is properly cited. 